\title{
Validation of gefitinib effectiveness in a broad panel of head and neck squamous carcinoma cells
}

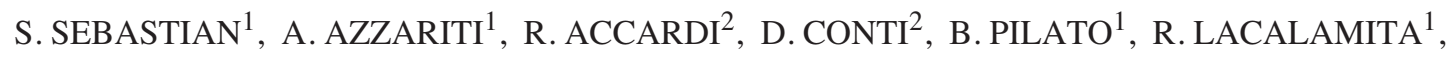 \\ L. PORCELLI ${ }^{1}$, G.M.SIMONE ${ }^{1}$, S. TOMMASI ${ }^{1}$, M. TOMMASINO ${ }^{2}$ and A. PARADISO ${ }^{1}$ \\ ${ }^{1}$ Clinical Experimental Oncology Laboratory, National Cancer Institute, Bari, Italy; ${ }^{2}$ Infection and Cancer Biology Group, \\ International Agency for Research on Cancer - World Health Organization (IARC), Lyon, France
}

Received September 3, 2007; Accepted November 5, 2007

\begin{abstract}
Recently improved understanding of the pathogenesis of human head and neck squamous cell carcinoma (HNSCC) has led to the development of new, molecularbased therapeutic strategies, one of the more promising is the utilisation of tyrosine kinase (TK) inhibitors, targeting epidermal growth factor receptor (EGFR). In this study, we tested for gefitinib effectiveness in a broad panel of 12 newly established HNSCC cell lines, investigating its ability to reduce cell growth, to induce apoptosis and to modulate cell cycle and various EGFR pathway-related targets. Gefitinib $\mathrm{IC}_{50}$ values ranged between 0.064 and $33 \mu \mathrm{M}$, its capability to induce apoptosis and cell accumulation in G0/G1 phase was cell line-specific, and the main EGFR-related pathway involved in gefitinib activity was PI3K/Akt/mTor. We characterised our in vitro panel extensively, with the aim to identify predictive factors for gefitinib effectiveness; all cell lines were free of human papillomavirus infection, two were positive for Fhit expression, four expressed wild-type p53, and all of them variously expressed the other two p53 family members, p63 and p73. The comparison between the targets analysed and gefitinib effectiveness evidenced the absence of a clear relationship, excluding them as predictive factors for gefitinib efficacy. Our results confirmed the in vitro efficacy of an anti-EGFR approach, but other targets than those analysed here should be characterised in order to identify valid predictive factors for gefitinib utilisation.
\end{abstract}

\section{Introduction}

Head and neck squamous cell carcinoma (HNSCC) is one of the most frequently occurring cancers worldwide, and the

Correspondence to: Dr Amalia Azzariti, Clinical Experimental Oncology Laboratory, National Cancer Institute, Via Hahnemann 10, 70125 Bari, Italy

E-mail: a.azzariti@oncologico.bari.it; amaliaris@yahoo.com

Key words: head and neck squamous carcinoma cell lines, molecular characterization, gefitinib sensitivity overall survival period is very short as the cancer often metastasises in the lymph nodes of the throat $(1,2)$. The failure of conventional chemotherapy, which does not increase the overall survival rate of patients, and the goal of identifying new biological targets for anticancer therapy, has stimulated the study of the molecular mechanisms of HNSCC progression (3-5). Among the promising new cellular targets, epidermal growth factor receptor (EGFR) seems to have a prominent role since it has been recognised as a prognostic factor in head and neck cancer $(6,7)$. It was recently suggested that gefitinib (ZD1839; Iressa), an orally active, selective EGFR tyrosine kinase (TK) inhibitor (8) could be utilised in head and neck cancer therapy $(9,10$ and www.clinicaltrials.gov). This drug is a quinazoline derivative that selectively inhibits EGFR tyrosine kinase activity by binding the receptor at the ATP-site, and is in clinical use in lung cancer patients (11). The utilisation of gefitinib in preclinical studies and early clinical trials has recently shown evidence of its promising activity in head and neck cancer treatment $(9,10,12)$. However, an important aspect that remains unclear in the utilisation of TK inhibitors relates to the difficulty of identifying any predictive factor that is applicable in all tumour types. It would therefore be of value to confirm the hypothesis that the efficacy of EGFR-targeting drugs in head and neck cancer is linked to EGFR tumour level, as recently suggested by Janmaat et al (13). Other biomarkers that have been suggested as predictive factors for gefitinib efficacy in other cancers, are increased EGFR gene copy number beyond EGFR protein expression, the presence of specific EGFR mutations and constitutive Akt activation (14-19).

In relation to other tumour types, an extensive pre-clinical analysis of the basic molecular mechanism involved in gefitinib-mediated anticancer effects in head and neck cancer is not available, e.g. in Shintani et al (20) gefitinib efficacy was investigated in only two HNSCC cell lines.

In this study, for the first time, the validation of gefitinib efficacy against head and neck cancer was performed in a broad panel of 12 newly established HNSCC cell lines and an extensive biological characterisation comprising cancer progression (including p53, Fhit, cell cycle characteristics and HPV infection) and EGFR-related markers (TK receptors, EGFR signal transduction pathway and ABCG2 expression), was also performed. 
Inactivating mutations of the p53 tumour suppressor gene are the most common genetic event identified for almost all human cancers, including HNSCC, and changes in p53 status have been linked to disease progression, decreased sensitivity to chemotherapeutic agents and poor prognosis (21). The key role of p53 in modulating EGFR expression (22-24) and in controlling cell proliferation and apoptosis poses the question of whether p53 status influences the efficacy of EGFR inhibitors. Moreover, the identification of two p53 homologues, p63 and p73 (25) with high identity of their amino acid sequence (about $63 \%$ in the DNA-binding domain) suggested a redundant function in the regulation of gene expression for these three transcription factors. p73 can activate p53-regulated genes, suppress growth or induce apoptosis (26). Furthermore, TAp63 and $\Delta$ Np63, two p63 isoforms, perform opposite functions, inducing cell-cycle arrest and cell proliferation respectively; the latter is frequently expressed in HNSCC (27).

Another factor analysed was Fhit (fragile histidine triad) which is frequently altered in head and neck cancer progression (28). It was recently demonstrated that the activation of EGFR family members induced Fhit phosphorylation by Src and the subsequent proteasome degradation of the phosphorylated Fhit protein (29), suggesting a key role for Fhit in the balance of proliferation/ survival/apoptosis signals and as a hypothetical predictive biomarker for gefitinib efficacy.

Another biological factor that has to be considered in head and neck cancer treatment with gefitinib, is human papillomavirus (HPV) status; HPV infection has been closely linked to oral cancer, with $30-40 \%$ of oral cancer biopsy specimens containing viral DNA of the high-risk HPV types, such as HPV-16, -18 and $-33(30,31)$.

The in vitro model was also characterised for the molecular alterations and expression of TK receptors and their downstream effectors (32). The main EGFR downstream effectors analysed were AKT and Erk1/2, involved in the survival and proliferation pathways respectively, and the tumour suppressor gene, PTEN, as its inactivation can induce resistance to TK inhibitors (33-35). The drug efflux pump ABCG2 (BCRP/MXR/ABCP) was also analysed in relation to gefitinib effectiveness in other cancer models (36-39). Finally, all HNSCC cell lines were analysed for the presence of mutations in the region of the EGFR gene coding for the tyrosine kinase domain (exon 18 to exon 21) and in the ATPase domain (exon 27 and 28) (18).

\section{Materials and methods}

Reagents. Gefitinib was provided by AstraZeneca Pharmaceuticals (London, UK). Stock solutions were prepared at $20 \mathrm{mM}$ in dimethyl sulfoxide (DMSO) and stored in aliquots at $-20^{\circ} \mathrm{C}$. The monoclonal antibody anti-EGFR was provided by BD Transduction Laboratories (USA); anti- 3 -actin antibody was purchased from Sigma (Milan, Italy); antiphosphotyrosine PY99, anti-Fhit, anti-PTEN, anti-VEGFR2, and anti- $\beta$-tubulin antibodies were provided by Santa Cruz Biotechnology (USA); anti-AKT, anti-phospho-AKT, antiERK1/2 and anti-phospho-ERK1/2 were provided by Cell Signaling (USA); anti-ABCG2 (human) MAb (BXP-21) by
Alexis Corporation; and p53 polyclonal antibody NCL-CM1 and p63 polyclonal antibody were from Novocastra. A mouse and a rabbit HRP (Amersham Pharmacia Biotech, Uppsala Sweden) were used as secondary antibodies.

Establishment of human HNSCC cell lines. The excised tumour masses from different tissues of the head and neck region consisted of larynx (one case, HNC-150), oral cavity (six cases, HNC-91, -97, -124, -160, -199, -212), tonsil (three cases, HNC-41, -206, -211), hypopharynx (one case, HNC180) and paranasal sinus (one case, HNC-136). These were minced and plated on dishes for explantation culture in DMEM supplemented with $20 \% \mathrm{FBS}, 50 \mathrm{ng} / \mathrm{ml}$ of EGF, $10 \mu \mathrm{g} / \mathrm{ml}$ of hydrocortisone, and $5 \mu \mathrm{g} / \mathrm{ml}$ of spermine. The tissue samples were obtained from cancer patients during oral surgery. Confluent primary cells were trypsinized and further cultured in DMEM supplemented with $10 \%$ FCS, $2 \mathrm{mM}$ glutamine and $2 \mathrm{mM}$ penicillin-streptomycin (Life Technologies), in a humidified incubator at $37^{\circ} \mathrm{C}$ with an atmosphere containing $5 \% \mathrm{CO}_{2}$.

Evaluation of cytotoxicity. Determination of the $\mathrm{IC}_{50}$ was performed using the 3-[4,5-dimethylthiazol-2-yl]-2,5diphenyltetrazoliumbromide (MTT) assay. On day 1, 12,000 cells/well in a volume of $200 \mu 1$ were plated in 96-well plates. In each plate, one column contained cells not exposed to drugs (control), and 5 columns contained cells exposed to increasing concentrations of gefitinib (from $10 \mathrm{nM}$ to $100 \mu \mathrm{M}$ ) for three days. Each drug concentration was repeated in at least 6 identical wells. Gefitinib was added on day 2, and results were expressed as dose-effect curves with a plot of the fraction of unaffected (surviving) cells versus drug concentration. The $\mathrm{IC}_{50}$ was defined as the drug concentration yielding a fraction of affected (non-surviving) cells (0.5) compared with untreated controls. Each experiment was conducted in triplicate.

Cell cycle analysis. Cells were exposed to gefitinib, harvested, washed twice in ice-cold PBS ( $\mathrm{pH} 7.4$ ), fixed in $4.5 \mathrm{ml}$ of $70 \%$ ethanol and stored at $-20^{\circ} \mathrm{C}$ for at least $24 \mathrm{~h}$. After being washed once in ice-cold PBS, the pellet was resuspended in PBS containing $1 \mathrm{mg} / \mathrm{ml}$ RNase and $0.01 \%$ NP40, and the cellular DNA was stained with $50 \mu \mathrm{g} / \mathrm{ml}$ propidium iodide (Sigma). Cells were stored in ice for $60 \mathrm{~min}$ prior to analysis. Cell cycle determinations were performed using a FACScan flow cytometer (Becton Dickinson), and data were interpreted using the CellQuest software, provided by the manufacturer. The DNA-ploidia pattern was evaluated comparing the shift of the G0/G1 peak of each cell line with respect to that of peripheral lymphocytes.

Determination of apoptosis. Exponentially growing cells were treated with gefitinib $\mathrm{IC}_{50}$ concentrations for 1-3 days. Apoptosis was evaluated using the Annexin V-FITC detection kit (BD Transduction) and by propidium iodide (PI) following the manufacturer's protocol.

Determination of human papillomavirus (HPV) infection. The presence of HPV (types 4, 5, 8, 9, 12, 14, 15, 17, 19-24, $26,36-38,47-50,60$ and 65) DNA was determined by 
reverse line blot hybridisation previously described by Kleter et al, 1999; Melchers et al, 1999 and Quint et al, 2001. Oligonucleotide probes specific for 24 different HPV types were covalently attached to a membrane in parallel lines using a miniblotter. The templates used for analysis were DNA extracts previously labeled with biotin, using PCR. The labeled PCR products were then loaded onto the membrane in slots perpendicular to the oligo lines in order to allow all samples to interact with the HPV probes. Hybridisation took place in the miniblotter and was visualised using a peroxidase-labeled streptavidine, which interacted with the biotin of the PCR products, followed by chemiluminescence detection.

Western blot analysis. Total proteins were extracted from the cell culture by homogenisation in a radioimmunoprecipitation assay (RIPA) buffer $[0.5 \mathrm{M} \mathrm{NaCl}, 1 \%$ Triton $\mathrm{X}-100,0.5 \%$ NP40, 1\% deoxycolic acid, $3.5 \mathrm{mM}$ sodium dodecyl sulfate (SDS)], with a $20 \%$ protease inhibitor cocktail (Sigma, MO), and measured by the Bradford method. Proteins were electrophoretically separated by Western blotting and signals were detected by chemiluminescence assay. Expression levels were evaluated by densitometric analysis using Quantity One software (Bio-Rad, Hercules, CA) and the $\beta$-actin expression level was used to normalise the sample values.

Immunoprecipitation assay. Cells were lysed in RIPA-IP buffer (140 mM NaCl, $20 \mathrm{mM}$ Tris/HCl, $10 \mathrm{mM}$ EDTA pH 8.0, $10 \%$ glycerol, 1\% NP40, $1 \mathrm{mM}$ Na-deoxycolic acid, $1 \mathrm{mM}$ PMSF), passed through a 22-gauge syringe and cleared by centrifugation at $10,000 \mathrm{x}$ g at $4^{\circ} \mathrm{C}$ for $10 \mathrm{~min}$. Proteins were immunoprecipitated by incubating $0.1-0.3 \mathrm{mg}$ of total cell lysate with $0.2 \mu \mathrm{g}$ of anti-phosphotyrosine antibody or EGFR antibody for $1 \mathrm{~h}$ at $4^{\circ} \mathrm{C}$. A/G agarose protein (2-5 $\mu \mathrm{l}$ ) (Santa Cruz Biotechnology) was incubated overnight at $4^{\circ} \mathrm{C}$. The cell suspension was centrifuged at 2,600 rpm and the pellet was washed three times with PBS and then re-suspended in $10 \mu 1$ of Laemmli buffer. Each sample was separated onto $10 \%$ acrylamide gel and Western blot analysis was performed as described above.

Reverse-transcription PCR. Each cell line was collected, the RNA was extracted with the Absolutely RNA Miniprep Kit (Stratagene) and $5 \mu \mathrm{g}$ of RNA was converted to cDNA using the First Strand cDNA Synthesis Kit (Fermentas MBI). The primers used for the PCR were as follows: $\triangle \mathrm{Np} 73,5^{\prime}-\mathrm{ACC}$ ATG CTG TAC GTC GGT GAC CCC-3' (forward) and 5'GCG ACA TGG TGT CGA AGG TGG AGC-3' (reverse); $\triangle \mathrm{Np} 63,5^{\prime}$-TGC CCA GAC TCA ATT TAG TGA G-3' (forward) and 5'-AGA GAG AGC ATC GAA GGT GGA G3' (reverse); TAp63, 5'-GAC CTG AGT GAC CCC ATG TG-3' (forward) and 5'-CGG GTG ATG GAG AGA GAG CA-3' (reverse). As a control, the following human GAPDH was used: 5'-AAG GTG GTG AAG CAG GCG T-3' and 5'GAG GAG TGG GTG TCG CTG TT-3'. Annealing temperatures and the number of cycles were specific for each isoform: $\Delta \mathrm{Np} 63,25$ cycles at $64^{\circ} \mathrm{C}$; TAp63, 35 cycles at $58^{\circ} \mathrm{C} ; \Delta \mathrm{Np} 73,40$ cycles at $62^{\circ} \mathrm{C}$; and TAp73, 35 cycles at $61^{\circ} \mathrm{C}$. The rest of the PCR amplification consisted of $94^{\circ} \mathrm{C}$ for $30 \mathrm{sec}$, for $30 \mathrm{sec}$, and $72^{\circ} \mathrm{C}$ for $30 \mathrm{sec}$ followed by
Table I. Primer sequences used for EGFR coding exon amplification.

\begin{tabular}{|c|c|}
\hline Exon & Primer sequence \\
\hline 18 & $\begin{array}{l}\text { Fw 5' CAAATGAGCTGGCAAGTGCCGTGTC 3' } \\
\text { Rv 5' GAGTTTCCCAAACACTCAGTGAAAC 3' }\end{array}$ \\
\hline 19 & $\begin{array}{l}\text { Fw 5' GCAATATCAGCCTTAGGTGCGGCT 3' } \\
\text { Rv 5' CATAGAAAGTGAACATTTAGGATGTG 3' }\end{array}$ \\
\hline 20 & $\begin{array}{l}\text { Fw 5' CCATGAGTACGTATTTTGAAACTC 3' } \\
\text { Rv 5' CATATCCCCATGGCAAACTCTTGC 3' }\end{array}$ \\
\hline 21 & $\begin{array}{l}\text { Fw 5' CTAACGTTCGCCAGCCATAAGTCC 3' } \\
\text { Rv 5' GCTGCGAGCTCACCCAGAATGTCTGG 3' }\end{array}$ \\
\hline 27 & $\begin{array}{l}\text { Fw 5' CAACCTACTAATCAGAACCAGCATC 3' } \\
\text { Rv 5' CCTTCACTGTGTCTGCAAATCTGC 3' }\end{array}$ \\
\hline $28 \mathrm{a}$ & $\begin{array}{l}\text { Fw 5' CCTGTCATAAGTCTCCTTGTTGAG 3' } \\
\text { Rv 5' GGTAGTCAGGGTTGTCCAGG 3' }\end{array}$ \\
\hline $28 b$ & $\begin{array}{l}\text { Fw 5' CGAGTATCTCAACACTGTCCAGC 3' } \\
\text { Rv 5' CTAATGCGGGCATGGTG 3' }\end{array}$ \\
\hline
\end{tabular}

incubation at $72^{\circ} \mathrm{C}$ for $7 \mathrm{~min}$. The bands were visualised by ethidium bromide staining.

DNA sequencing analysis. Randomly primed cDNAs were reverse-transcribed from $5 \mu \mathrm{g}$ of total RNA using First Strand cDNA Synthesis Kit in a 40- $\mu 1$ mixture. Two microlitres of the cDNA mixture was used to amplify the p53 transcript (exons 4-9). PCR products were cloned into PCR II using a TA $^{\mathrm{TM}}$ Cloning Kit (Invitrogen, San Diego, CA) under the conditions recommended by the manufacturer. The nucleotide sequence of the cloned DNA was determined by a Taq Dideoxy Terminator Cyclic Sequencing Kit on an ABI 377 Automatic DNA Sequencer (PerkinElmer, Foster City, CA).

Mutational analysis of EGFR. Genomic DNA was extracted from each cell line, using QIAamp DNA Blood Midi Kit (Qiagen) following the manufacturer's instructions. DNA was quantified and mutational analysis was performed from EGFR exons 18 to 21 and in exons 27 and 28. EGFR coding exon was amplified by PCR using the primers described in Table I.

PCR amplification was carried out in a total volume of $50 \mu \mathrm{l}$ containing $150 \mathrm{ng}$ of genomic DNA as template, $1 \mathrm{X}$ reaction buffer, 1.5-3 mM magnesium chloride, $200 \mathrm{mM}$ dNTP, 20-50 pmol of each PCR primer and 0.25 U AmpliTaq Gold. After PCR amplifications, $5 \mu 1$ of the reaction product was analysed via gel electrophoresis and ethidium bromide staining. DNA sequencing was performed on both strands of two independent PCR products by cycle sequencing on an ABI PRISM 310 automated cycle sequencer, using the Terminator Cycle Sequencing Kit v.1.1 according to the manufacturer's protocol (Applied Biosystems, 
Table II. Gefitinib effectiveness in HNSCC cell lines.

\begin{tabular}{|c|c|c|c|c|c|c|c|}
\hline \multirow[t]{2}{*}{ Cell line } & \multirow[t]{2}{*}{ Site of origin } & \multicolumn{6}{|c|}{ 3-day gefitinib treatment } \\
\hline & & $\begin{array}{l}\mathrm{IC}_{50}(\mu \mathrm{M}) \\
\quad \pm \mathrm{SD}\end{array}$ & $\begin{array}{c}\mathrm{G} 0 / \mathrm{G} 1 \\
\text { increase \% }\end{array}$ & Apoptosis & $\begin{array}{c}\text { p-EGFR } \\
\text { expression } \%\end{array}$ & $\begin{array}{c}\text { p-AKT } \\
\text { expression } \%\end{array}$ & $\begin{array}{c}\mathrm{p}-\mathrm{Erk} 1 / 2 \\
\text { expression } \%\end{array}$ \\
\hline HNC-211 & Tonsil & $0.064 \pm 0.01$ & 9 & + & ND & 20 & 40 \\
\hline HNC-180 & Hypopharynx & $0.71 \pm 0.12$ & 17 & - & ND & 10 & 0 \\
\hline HNC-97 & Oral cavity & $1.9 \pm 0.9$ & 1 & - & ND & 0 & 50 \\
\hline HNC-97 & Oral cavity & $1.9 \pm 0.9$ & 1 & - & ND & 0 & 80 \\
\hline HNC-124 & Oral cavity & $1.9 \pm 1.2$ & 7 & + & ND & 0 & ND \\
\hline HNC-160 & Oral cavity & $2.2 \pm 1.1$ & 1 & - & ND & 10 & 0 \\
\hline HNC-212 & Oral cavity & $4.22 \pm 1.8$ & 9 & - & 80 & 0 & 10 \\
\hline HNC-212 & Oral cavity & $4.22 \pm 1.8$ & 9 & - & ND & 0 & 10 \\
\hline HNC-91 & Oral cavity & $5.3 \pm 2.0$ & 4 & - & ND & 100 & 100 \\
\hline HNC-41 & Tonsil & $5.4 \pm 1.6$ & 0 & - & ND & 0 & ND \\
\hline HNC-206 & Tonsil & $8.3 \pm 2.4$ & 22 & - & 80 & 30 & 100 \\
\hline HNC-136 & Paranasal sinus & $9.3 \pm 1.9$ & 5 & + & ND & ND & ND \\
\hline HNC-199 & Oral cavity & $25 \pm 3.3$ & 7 & + & ND & 100 & 100 \\
\hline HNC-150 & Larynx & $33 \pm 2.7$ & 0 & + & ND & 30 & 100 \\
\hline
\end{tabular}

CA). Whenever an alteration was identified, a new DNA aliquot from the same cell line was sequenced to confirm the result. The variants found in the sequence were characterised and compared to those in the online databases, EntrezSNP (http://www.ncbi.nlm.nih.gov) and Ensembl (www.ensembl.org).

\section{Results}

The in vitro validation of gefitinib effectiveness in head and neck cancer was performed in a broad panel of head and neck cancer cell lines. Firstly, we investigated the efficacy of gefitinib. We then analysed our in vitro model for several characteristics connected with cancer progression (including p53, Fhit, cell cycle characteristics and HPV infection), and the anti-tumour activity of EGFR inhibitors (TK receptors, EGFR signal transduction pathway, ABCG2 expression and the presence of mutations in the region of the EGFR gene coding for the tyrosine kinase and ATPase domains), with the aim of identifying predictive factors for this TK inhibitor activity.

Gefitinib effectiveness. A broad panel of 12 HNSCC cell lines was established from different tissues of the head and neck area and stabilised (Table II). This panel could be considered representative of head and neck cancer in in vitro studies.

The capability of gefitinib to inhibit cell growth was determined by incubating each HNSCC cell line with various drug concentrations for 3 days, and the results are reported as $\mathrm{IC}_{50}$ values in Table II. Out of all cell lines, HNC-211 cells were the most sensitive to the drug, with $\mathrm{IC}_{50}$ of $64 \mathrm{nM}$, and the most resistant ones were HNC-150 and -199 ( $\mathrm{IC}_{50}$ of 25 and $33 \mu \mathrm{M}$, respectively). The other cell lines showed 10- to 300 -fold greater resistance to the drug than HNC-211.

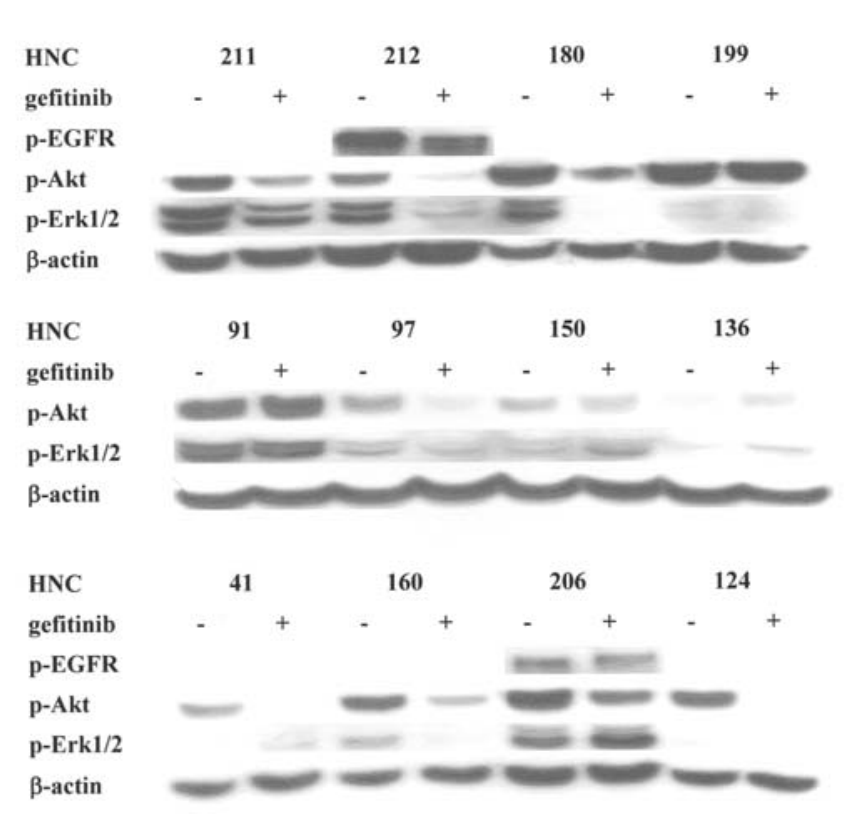

Figure 1. EGFR pathway modulation by gefitinib. HNSCC cells were incubated with gefitinib at $\mathrm{IC}_{50}$ concentration and the protein extracts were analysed by immunoprecipitation and/or Western blotting. In Western blot analysis, the amount of the different targets was determined using monoclonal- or polyclonal- specific antibodies and $\beta$-actin was used to normalise the values. p-EGFR was clearly detectable only in HCN-212 and HCN-206.

Then, the capability of gefitinib to induce apoptosis was investigated by treating all cell lines with gefitinib at $\mathrm{IC}_{50}$ concentration for 1-3 days. A 10-20\% increase in Annexin $\mathrm{V}$-positive cells was evident in only five cell lines: HNC-211, $-124,-136,-199$ and -150 ; the only difference among them was that the first two underwent apoptosis early (1-2 days) and this phenomenon decreased during the third day, while the 
Table III. Characterisation of HNSCC cell lines.

\begin{tabular}{|c|c|c|c|c|c|c|c|c|c|c|c|}
\hline \multirow[t]{2}{*}{ Cell line } & \multirow{2}{*}{$\begin{array}{l}\mathrm{IC}_{50}(\mu \mathrm{M}) \\
\quad \pm \mathrm{SD}\end{array}$} & \multicolumn{4}{|c|}{ p53 } & \multirow[t]{2}{*}{$\Delta \mathrm{Np} 73$} & \multirow[t]{2}{*}{ TAp73 } & \multirow[t]{2}{*}{$\Delta \mathrm{Np} 63$} & \multirow{2}{*}{ TAp63 } & \multirow{2}{*}{$\frac{\mathrm{p} 63}{\begin{array}{c}\text { Protein } \\
\text { expression }\end{array}}$} & \multirow[t]{2}{*}{ Fhit } \\
\hline & & Exon & Codon base & $\begin{array}{l}\text { Amino acid } \\
\text { change }\end{array}$ & $\begin{array}{l}\text { Protein } \\
\text { expression }\end{array}$ & & & & & & \\
\hline HNC-211 & $0.064 \pm 0.01$ & 6 & 177-183 Del 5 & In frame & + & + & - & + & + & + & - \\
\hline HNC-180 & $0.71 \pm 0.12$ & 6 & 220 TㅁT-TGT & Tyr-Cys & - & - & - & + & + & + & - \\
\hline HNC-97 & $1.9 \pm 0.9$ & 5 & $180 \underline{\mathrm{G} A G}-\underline{\mathrm{A}} \mathrm{AG}$ & Glu-Lys & - & + & - & + & + & + & - \\
\hline HNC-97 & $1.9 \pm 0.9$ & 7 & $248 \underline{\text { CGG-TGG }}$ & Arg-Trp & - & + & - & + & + & + & - \\
\hline HNC-124 & $1.9 \pm 1.2$ & $(4-9)$ & WT & - & ++ & + & - & + & + & + & - \\
\hline HNC-160 & $2.2 \pm 1.1$ & 6 & $213 \mathrm{CG} \underline{\mathrm{A}}-\mathrm{CG} \underline{\mathrm{G}}$ & Arg-Arg & - & + & - & + & + & + & - \\
\hline HNC-212 & $4.22 \pm 1.8$ & 6 & 196 C $\underline{G A}-C \underline{C A}$ & Arg-Pro & ++ & - & - & + & + & + & - \\
\hline HNC-212 & $4.22 \pm 1.8$ & 9 & 331 CAG-.AG & Frameshift & ++ & - & - & + & + & - & - \\
\hline HNC-91 & $5.3 \pm 2.0$ & $(4-9)$ & WT & - & - & + & - & - & + & - & + \\
\hline HNC-41 & $5.4 \pm 1.6$ & $(4-9)$ & WT & - & - & - & + & + & + & + & - \\
\hline HNC-206 & $8.3 \pm 2.4$ & 5 & 134 TTT-TET & Phe-Ser & - & - & - & + & + & + & + \\
\hline HNC-136 & $9.3 \pm 1.9$ & $(4-9)$ & WT & - & +++ & + & + & - & + & - & - \\
\hline HNC-199 & $25 \pm 3.3$ & 5 & 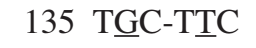 & Cys-Phe & - & + & - & + & + & + & - \\
\hline HNC-150 & $33 \pm 2.7$ & 5 & 135 T $\underline{\text { GC}}-\mathrm{T} \underline{\mathrm{A}} \mathrm{C}$ & Cys-Tyr & - & + & - & + & + & + & - \\
\hline
\end{tabular}

last three showed progressive increase in Annexin V-positive cells as a function of time exposure (data not shown). The high variability of $\mathrm{IC}_{50}$ values suggested the need to investigate the gefitinib activity in each cell line. In particular, the ability of gefitinib to modulate cell cycle progression was determined. A three-day drug exposure induced a slight blockage of the cell cycle at G0/G1 phase, with a maximum effect in HNC-206 inducing an increase in the accumulation of G0/G1 phase cells of $22 \%$ (Table II).

The drug-dependent modulation of EGFR and its downstream effectors, Akt and Erk1/2, was also investigated. Each cell line was treated with gefitinib at each $\mathrm{IC}_{50}$ concentration for three days and the modulation of total and phosphorylated forms of EGFR, Erk1/2 and Akt was analysed. Gefitinib did not modulate the expression of EGFR, Akt and Erk1/2 (data not shown). Only HNC-212 and -206 cells showed detectable levels of p-EGFR expression and a 3-day gefitinib treatment showed $80 \%$ of residual EGFR in the phosphorylated form (Fig. 1). p-Akt was completely abolished by gefitinib in four cell lines, HNC-41,-124, -97 and -212, and variously reduced in the remainder, conversely p-Erk1/2 was reduced to a lesser extent with the exception of HCN-180 and -160, as reported in Fig. 1 and summarised in Table II.

Cell line characterisation. With the aim of identifying cellular or molecular factors that are predictive of gefitinib efficacy in our panel of head and neck cell lines, each cell line was characterised for targets related to cancer progression and drug activity.

In detail, expression and cell cycle distribution of Fhit and p53 family, were determined. As summarised in Table III, Fhit, the tumour suppressor that is frequently altered in head and neck cancer, was expressed only in two cell lines and a sequence analysis of exons 4-9 of the p53 gene provided evidence that 8 cell lines had mutated p53 and only four cell lines, either wild-type and mutated (HNC-124, -136, -211, -212), exhibited detectable levels of p53. Other p53 homologues analysed in our in vitro panel were p63 (TAp63, $\Delta$ Np63) and p73 (TAp73, $\Delta$ Np73). A preliminary RT-PCR analysis of $\Delta \mathrm{Np} 73$ showed that it was detectable only in HNC-150 and -211 , while a following nested PCR evidenced its presence in $75 \%$ of all the cell lines (Fig. 2A). TAp73 was detectable only in HNC-41 and HNC-136 by both RT-PCR and nested PCR (Fig. 2B). Concerning p63 isoforms, $\triangle$ Np63 seemed to be overexpressed in eight cell lines by RT-PCR analysis, while nested PCR showed two more cell lines that were positive for this isoform expression (Fig. 2C). The high expression level of $\triangle \mathrm{Np} 63$ in HNSCC cell lines was confirmed by Western blot analysis and the results are shown in Fig. 2E. The expression levels of TAp63 were also analysed by RT-PCR and nested PCR, and it seemed to be present in all cell lines (Fig. 2D). Cell cycle analysis showed that all cell lines had an atypical distribution in the G0/G1, S and $\mathrm{G} 2 / \mathrm{M}$ phases and, with respect to lymphocytes, they were all aneuploid with a DNA index ranging between 1.13 and 1.75 (data not shown). Moreover, HNSCC cell lines analysed for the presence of HPV DNA (types 4, 5, 8, 9, 12, 14, 15, $17,19-24,26,36-38,47-50,60$ and 65) showed that it was absent (data not shown).

Our in vitro model was then analysed for several characteristics related to the mechanism of action of TK inhibitors, such as the expression levels of EGFR, p-EGFR, ErbB2, VEGFR-2, Erk1/2, p-Erk1/2, PTEN, Akt, and p-Akt. Higher levels of EGFR were observed in HNC-211, -199, and -206 cells whereas it was undetectable in HNC-91 and -136 . Conversely, only HNC-206 and -212 showed detectable levels of p-EGFR (Fig. 3). The other two TK receptors, ErbB2 and VEGFR-2, and the two signal transduction pathway effectors, Akt and Erk1/2, were ubiquitously expressed in all cell lines (Fig. 3). Conversely, p-Akt and p-Erk1/2 
A
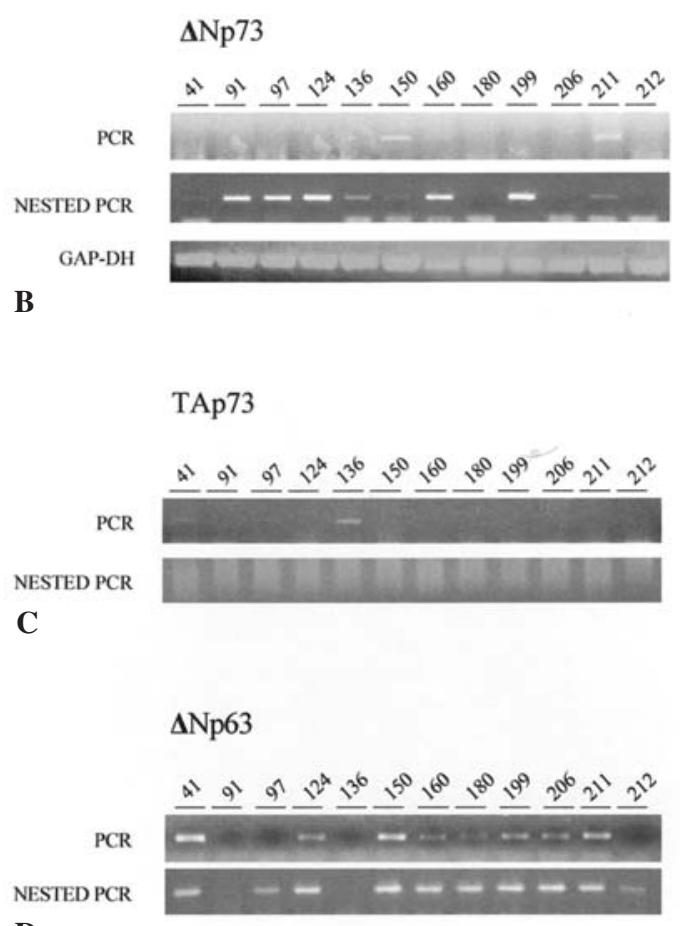

D

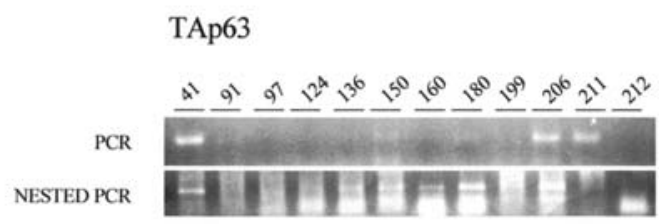

$\mathbf{E}$

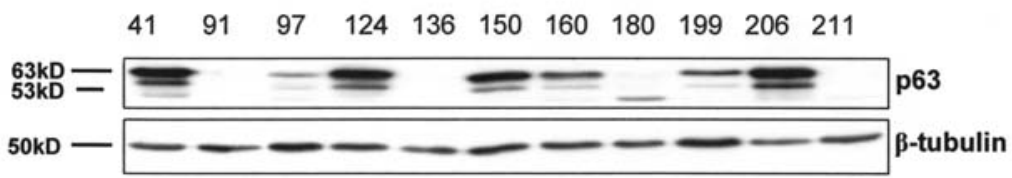

Figure 2. p63 and p73 characterisation in HNSCC cell lines. The isoforms of p73 [(A) $\Delta$ Np73, (B) TAp73] and p63 [(C) $\Delta$ Np63, (D) TAp63] and were analysed by PCR and nested PCR in all cell lines; protein was determined only for p63.

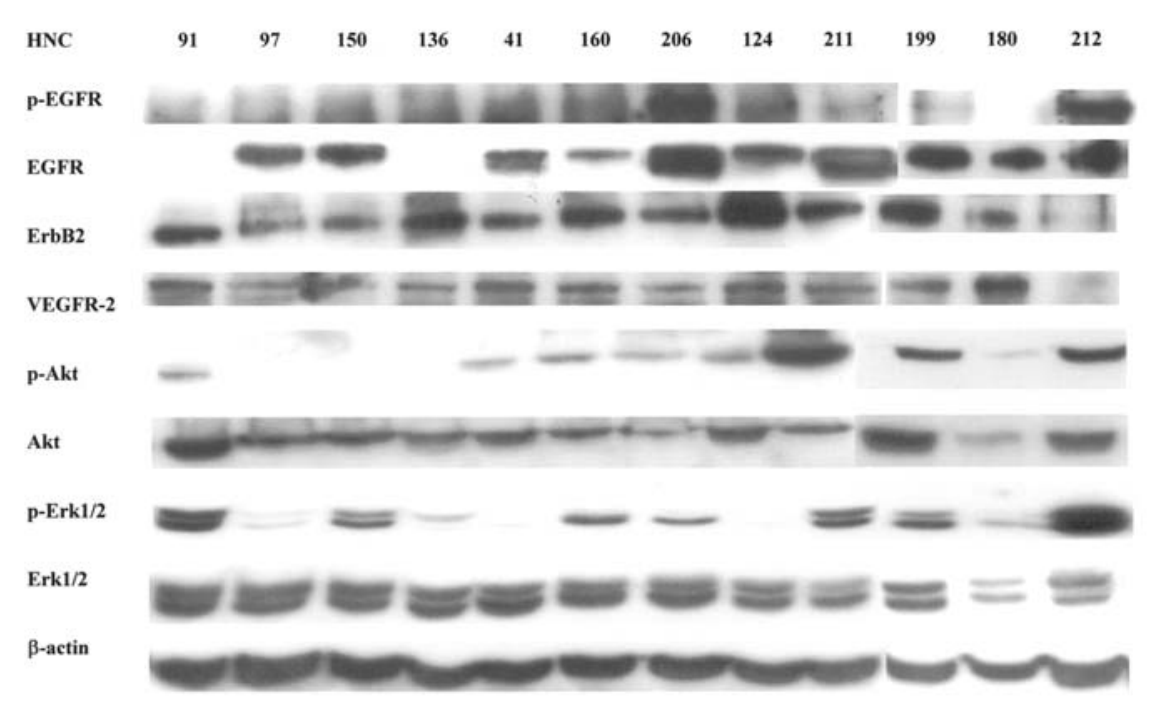

Figure 3. TK receptor and downstream effector expression in HNSCC cell lines. EGFR, ErbB2, VEGFR-2, Erk1/2, p-Erk1/2, Akt and p-Akt expression in HNSCC cellular extracts was analysed by Western blotting. Phosphorylated EGFR was determined by immunoprecipitation followed by Western blotting. 
Table IV. Characterisation of HNSCC cell lines.

\begin{tabular}{|c|c|c|c|c|c|c|c|}
\hline \multirow[t]{2}{*}{ Cell lines } & \multirow[t]{2}{*}{$\mathrm{IC}_{50}(\mu \mathrm{M}) \pm \mathrm{SD}$} & \multicolumn{5}{|c|}{ Basal protein expression $\%$} & \multirow[b]{2}{*}{$\mathrm{ABCG} 2$} \\
\hline & & EGFR & p-EGFR & p-Akt & p-Erk1/2 & PTEN & \\
\hline HNC-211 & $0.064 \pm 0.01$ & + & +++ & +++ & ++ & + & + \\
\hline HNC-180 & $0.71 \pm 0.12$ & - & ++ & - & + & +++ & +++ \\
\hline HNC-97 & $1.9 \pm 0.9$ & ++ & ++ & - & - & + & + \\
\hline HNC-97 & $1.9 \pm 0.9$ & ++ & ++ & - & - & + & + \\
\hline HNC-124 & $1.9 \pm 1.2$ & ++ & ++ & + & - & ++ & ++ \\
\hline HNC-160 & $2.2 \pm 1.1$ & ++ & + & + & + & ++ & + \\
\hline HNC-212 & $4.22 \pm 1.8$ & +++ & +++ & ++ & +++ & ++ & + \\
\hline HNC-212 & $4.22 \pm 1.8$ & +++ & +++ & ++ & +++ & ++ & + \\
\hline HNC-91 & $5.3 \pm 2.0$ & ++ & - & + & +++ & +++ & ++ \\
\hline HNC-41 & $5.4 \pm 1.6$ & ++ & + & + & - & +++ & + \\
\hline HNC-206 & $8.3 \pm 2.4$ & +++ & +++ & + & + & + & ++ \\
\hline HNC-136 & $9.3 \pm 1.9$ & ++ & - & - & - & +++ & ++ \\
\hline HNC-199 & $25 \pm 3.3$ & + & ++ & ++ & ++ & +++ & +++ \\
\hline HNC-150 & $33 \pm 2.7$ & ++ & ++ & - & ++ & ++ & + \\
\hline
\end{tabular}
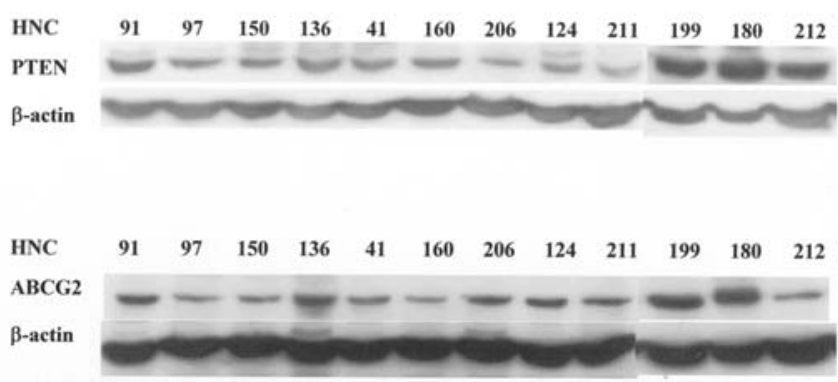

Figure 4. PTEN and ABCG2 expression in HNSCC cell lines. PTEN and ABCG-2 expression in HNSCC cellular extracts was analysed by Western blotting, utilising $\beta$-actin as the internal standard.

expression varied among cell lines, with higher levels of the former in HCN-211 and of the latter, in HCN-212 and -91 (Fig. 3). The tumour suppressor PTEN, was expressed ubiquitously in all cell lines (Fig. 4). Recent evidence of a relationship between gefitinib and ABCG2 prompted us to characterise this drug efflux pump in our in vitro model; it was expressed in all cell lines with a higher expression in HNC-180, -199 and -136 (Fig. 4). The results of the various cellular targets analysed are summarised in Table IV.

Finally, mutational analysis, performed in the region of the EGFR gene coding for the tyrosine kinase domain and in the ATPase domain, showed that all cell lines were wildtype. However, this characterisation, utilising primers designed for $\sim 150$ nucleotides downstream and upstream of the exonic region, evidenced intronic variants. $\mathrm{HCN}-211$ presented IVS17-104 C>A and IVS18+103 C>T intronic variants while $\mathrm{HCN}-41$ cell line only IVS17-104 C>A. Intron 19 presented two different types of intronic variants: IVS19+96 A>G in HCN-91 and HCN-211, and IVS 19-60 in HCN-41, -91, -199 and -211. However, these intronic variants did not appear to interfere with the modification of EGFR expression.

\section{Discussion}

The validity of our in vitro model for a complete analysis of gefitinib activity in HNSCC is supported by the evaluation of gefitinib efficacy in this panel, characterised by significant cell line-specific drug variability, i.e. HNC-211, was highly sensitive $\left(\mathrm{IC}_{50}\right.$ in nanomolar range) while $\mathrm{HNC}-150$ showed the highest resistance $\left(\mathrm{IC}_{50}=33 \mu \mathrm{M}\right)$. Moreover, gefitinib was able to induce apoptosis after 3 days of exposure mainly in the most resistant cell lines. This was probably due to the high drug concentration responsive to a non-specificity of action. Notably, this TK inhibitor also induced apoptosis in two sensitive cell lines, suggesting that its ability to initiate the apoptotic process could be cell line-specific. This idea is supported by the evidence that in the resistant cells, apoptosis increased in a time-dependent manner leading to the hypothesis that the mechanism of drug saturation could be involved. Analysis of the modulation of EGFR signal transduction pathways by gefitinib showed that this drug, after three days of exposure, did not seem to inhibit EGFR phosphorylation. However, based on our previous evidence (40), we hypothesised that gefitinib inhibited EGFR activation early on, while after a prolonged exposure (3 days), the phosphorylated form of the receptor recovered its baseline level. Analysis of the ability of gefitinib to reduce the activation of the two main signal transduction pathways, $\mathrm{PI} 3 \mathrm{~K} / \mathrm{Akt} / \mathrm{mT}$ or and Ras/MAPK, was evidenced by a selective action on the first of these targets. Furthermore, PTEN was similarly expressed in all cell lines, in agreement with a low percentage of the inactivated form of this tumour suppressor reported in head and neck cancer $(33,41)$, and the ubiquitous expression of $\mathrm{ABCG} 2$ did not allow the hypothesis of any correlation of this drug efflux pump with gefitinib sensitivity.

The cell variability for drug sensitivity suggested that we characterise our in vitro panel of HNSCC cell lines searching for predictive factors for gefitinib efficacy. We considered all biological characteristics involved in head and neck 
tumour progression, such as HPV infection, ploidia, Fhit characteristics and p53 family expression. High-risk HPVs have been frequently found in $\operatorname{HNSCC}(30,31)$ but unfortunately, none of the 12 HNSCC cell lines showed the presence of HPV DNA (types 4, 5, 8, 9, 12, 14, 15, 17, 1924, 26, 36-38, 47-50, 60 and 65). Moreover, only two cell lines, with medium sensitivity to gefitinib, were positive for Fhit expression suggesting that this factor is not directly correlated with the activity of this drug. The analysis of p53 family expression showed a variable distribution of cell lines with mutated p53 and/or the presence of the various isoforms of p63 and p73. No dependency on the drug activity was shown by the status of the p53 family. All cell lines were aneuploid with no difference between the most and the least sensitive lines. The lack of a dependency of gefitinib efficacy on the above described factors involved in head and neck cancer progression, prompted us to investigate the existence of a correlation between the activity of this drug and the expression level of cellular targets, such as TK receptors, downstream effectors, PTEN, and ABCG2, a drug efflux pump recently linked with gefitinib response (36-39). As reported in Table IV, the different distribution of the total and active forms of these targets did not allow the identification of any predictive factors, confirming that, as in other tumour types, gefitinib effectiveness in head and neck tumours, is not directly correlated with its target, EGFR. Finally, based on evidence that in lung cancer, certain mutations in the region of the EGFR gene coding for the ATPase and tyrosine kinase domains are related to drug sensitivity, we analysed our 12 cell lines for EGFR mutation status, confirming the data of Puhringer-Oppermann et al which suggested that these mutations are not relevant in determining gefitinib response in oral cancer (42).

Although our cell characterisation did not identify any valid predictive factor for gefitinib effectiveness, the comparison between p53 family and EGFR expression suggested, for the first time, a correlation between the $\Delta \mathrm{Np} 63$ isoform and EGFR expression level.

Transcription factors of the p53 family are mainly considered to be tumour suppressors, even though recent evidence demonstrated opposite functions for the p63 isoforms, $\Delta \mathrm{Np} 63$ and TAp63, promoting cell proliferation and mimicking tumour suppressor p53 respectively (27). Moreover, p53 family transcription factors are involved in the regulation of EGFR expression $(23,24)$. In our study, two of the HNSCC cell lines did not express either $\triangle \mathrm{Np} 63$ or EGFR, while the remainder co-expressed both proteins, suggesting a direct correlation between EGFR and $\Delta \mathrm{Np} 63$ expression in the development of head and neck squamous cell carcinomas.

In conclusion, our study, performed in a broad panel of HNSCC cell lines, strongly confirmed the validity of gefitinib utilisation in head and neck cancer, however, it also demonstrated an urgent need to identify some valid predictive factors for the utilisation of tyrosine kinase inhibitors.

\section{Acknowledgements}

This study was supported by grants from the Italian Association for Cancer Research (AIRC - 2006).

\section{References}

1. Lacau St Guily JL: Current trends in diagnosis and treatment of head and neck cancer. Rev Prat 56: 1652-1657, 2006.

2. Zender CA and Petruzzelli GJ: Why do patients with head and neck squamous cell carcinoma experience distant metastases: can they be prevented? Curr Opin Otolaryngol Head Neck Surg 13: 101-104, 2005.

3. St John MA, Abemayor E and Wong DT: Recent new approaches to the treatment of head and neck cancer. Anticancer Drugs 17: 365-375, 2006

4. Astsaturov I, Cohen RB and Harari PM: EGFR-targeting monoclonal antibodies in head and neck cancer. Curr Cancer Drug Targets 6: 691-710, 2006.

5. Astsaturov I, Cohen RB and Harari P: Targeting epidermal growth factor receptor signaling in the treatment of head and neck cancer. Expert Rev Anticancer Ther 6: 1179-1193, 2006.

6. Dassonville O, Formento JL, Francoual M, et al: Expression of epidermal growth factor receptor and survival in upper aerodigestive tract cancer. J Clin Oncol 11: 1873-1878, 1993.

7. Etienne MC, Pivot X, Formento JL, et al: A multifactorial approach including tumoural epidermal growth factor receptor, p53, thymidylate synthase and dihydropyrimidine dehydrogenase to predict treatment outcome in head and neck cancer patients receiving 5-fluorouracil. Br J Cancer 79: 1864-1869, 1999.

8. Mendelsohn J and Baselga J: Epidermal growth factor receptor targeting in cancer. Semin Oncol 33: 369-385, 2006.

9. Saba NF, Khuri FR and Shin DM: Targeting the epidermal growth factor receptor. Trials in head and neck and lung cancer. Oncology 20: 153-161, 2006.

10. Vokes EE and Chu E: Anti-EGFR therapies: clinical experience in colorectal, lung, and head and neck cancers. Oncology 20 (Suppl 2): 15-25, 2006.

11. Cohen MH, Williams GA, Sridhara R, et al: United States Food and Drug Administration Drug Approval summary: Gefitinib (ZD1839; Iressa) tablets. Clin Cancer Res 10: 1212-1218, 2004.

12. Erjala K, Sundvall M, Junttila TT, et al: Signaling via ErbB2 and ErbB3 associates with resistance and epidermal growth factor receptor (EGFR) amplification with sensitivity to EGFR inhibitor gefitinib in head and neck squamous cell carcinoma cells. Clin Cancer Res 12: 4103-4111, 2006.

13. Janmaat ML, Gallegos-Ruiz MI, Rodriguez JA, et al: Predictive factors for outcome in a phase II study of gefitinib in secondline treatment of advanced esophageal cancer patients. J Clin Oncol 24: 1612-1619, 2006.

14. Hirsch FR, Varella-Garcia M, Cappuzzo F, et al: Combination of EGFR gene copy number and protein expression predicts outcome for advanced non-small-cell lung cancer patients treated with gefitinib. Ann Oncol 18: 752-760, 2007.

15. Han SW, Kim TY, Hwang PG, Jeong S, Kim J, Choi IS, Oh DY, Kim JH, Kim DW, Chung DH, Im SA, Kim YT, Lee JS, Heo DS, Bang YJ, and Kim NK: Predictive and prognostic impact of epidermal growth factor receptor mutation in non-small-cell lung cancer patients treated with gefitinib. J Clin Oncol 23: 2493-2501, 2005.

16. Pao W and Miller VA: Epidermal growth factor receptor mutations, small-molecule kinase inhibitors, and non-small-cell lung cancer: current knowledge and future directions. J Clin Oncol 23: 2556-2568, 2005.

17. Cappuzzo F, Hirsch FR, Rossi E, Bartolini S, Ceresoli GL, Bemis L, Haney J, Witta S, Danenberg K, Domenichini I, Ludovini V, Magrini E, Gregorc V, Doglioni C, Sidoni A, Tonato M, Franklin WA, Crino L, Bunn PA Jr and Varella-Garcia M: Epidermal growth factor receptor gene and protein and gefitinib sensitivity in nonsmall-cell lung cancer. J Natl Cancer Inst 97: 643-655, 2005.

18. Lynch TJ, Bell DW, Sordella R, et al: Activating mutations in the epidermal growth factor receptor underlying responsiveness of non-small-cell lung cancer to gefitinib. N Engl J Med 350: 2129-2139, 2004.

19. Mulloy R, Ferrand A, Kim Y, et al: Epidermal growth factor receptor mutants from human lung cancers exhibit enhanced catalytic activity and increased sensitivity to gefitinib. Cancer Res 67: 2325-2330, 2007

20. Shintani S, Li C, Mihara M, et al: Gefitinib ('Iressa', ZD1839), an epidermal growth factor receptor tyrosine kinase inhibitor, up-regulates p27KIP1 and induces G1 arrest in oral squamous cell carcinoma cell lines. Oral Oncol 40: 43-51, 2004.

21. Strano S, Dell'Orso S, Di Agostino S, Fontemaggi G, Sacchi A and Blandino G: Mutant p53: an oncogenic transcription factor. Oncogene 26: 2212-2219, 2007. 
22. Sheikh MS, Carrier F, Johnson AC, Ogdon SE and Fornace AJ Jr: Identification of an additional p53-responsive site in the human epidermal growth factor receptor gene promotor. Oncogene 15: 1095-1101, 1997.

23. Deb SP, Munoz RM, Brown DR, Subler MA and Deb S: Wildtype human p53 activates the human epidermal growth factor receptor promoter. Oncogene 9: 1341-1349, 1994.

24. Nishi H, Senoo M, Nishi KH, et al: p53 homologue p63 represses epidermal growth factor receptor expression. J Biol Chem 276: 41717-41724, 2001.

25. Levrero M, De Laurenzi V, Costanzo A, Gong J, Wang JY and Melino G: The p53/p63/p73 family of transcription factors: overlapping and distinct functions. J Cell Sci 113: 1661-1670, 2000.

26. Stiewe T: The p53 family in differentiation and tumorigenesis. Nat Rev Cancer 7: 165-168, 2007.

27. Foschini MP, Gaiba A, Cocchi R, et al: Pattern of p63 expression in squamous cell carcinoma of the oral cavity. Virchows Arch 444: 332-339, 2004.

28. Paradiso A, Ranieri G, Stea B, et al: Altered p16INK4a and Fhit expression in carcinogenesis and progression of human oral cancer. Int J Oncol 24: 249-255, 2004.

29. Bianchi F, Magnifico A, Olgiati C, et al: FHIT-proteasome degradation caused by mitogenic stimulation of the EGF receptor family in cancer cells. Proc Natl Acad Sci USA 103: 18981-18986, 2006.

30. Shima K, Kobayashi I, Saito I, et al: Incidence of human papillomavirus 16 and 18 infection and p53 mutation in patients with oral squamous cell carcinoma in Japan. Br J Oral Maxillofac Surg 38: 445-450, 2000.

31. Syrjanen S: Viral infections in oral mucosa. Scand J Dent Res 100: 17-31, 1992.

32. Ichinose J, Murata M, Yanagida T and Sako Y: EGF signalling amplification induced by dynamic clustering of EGFR. Biochem Biophys Res Commun 324: 1143-1149, 2004.

33. Mavros A, Hahn M, Wieland I, et al: Infrequent genetic alterations of the tumor suppressor gene PTEN/MMAC1 in squamous cell carcinoma of the oral cavity. J Oral Pathol Med 31: 270-276, 2002.
34. Chen Q, Samaranayake LP, Zhou H and Xiao L: Homozygous deletion of the PTEN tumor-suppressor gene is not a feature in oral squamous cell carcinoma. Oral Oncol 36: 95-99, 2000.

35. Shin KH, Kim JM, Rho KS, Park KH, Oh JE and Min BM: Inactivation of the PTEN gene by mutation, exonic deletion, and loss of transcript in human oral squamous cell carcinomas. Int J Oncol 21: 997-1001, 2002.

36. Azzariti A, Porcelli L, Xu JM, Simone GM and Paradiso A Prolonged exposure of colon cancer cells to the epidermal growth factor receptor inhibitor gefitinib (Iressa ${ }^{\mathrm{TM}}$ ) and to the antiangiogenic agent ZD6474: Cytotoxic and biomolecular effects. World J Gastroenterol 12: 5140-5147, 2006.

37. Leggas M, Panetta JC, Zhuang Y, et al: Gefitinib modulates the function of multiple ATP-binding cassette transporters in vivo. Cancer Res 66: 4802-4807, 2006.

38. Nagashima S, Soda H, Oka M, et al: BCRP/ABCG2 levels account for the resistance to topoisomerase I inhibitors and reversal effects by gefitinib in non-small cell lung cancer. Cancer Chemother Pharmacol 58: 594-600, 2006.

39. Elkind NB, Szentpetery Z, Apati A, et al: Multidrug transporter ABCG2 prevents tumor cell death induced by the epidermal growth factor receptor inhibitor Iressa (ZD1839, gefitinib). Cancer Res 65: 1770-1777, 2005.

40. Giannelli G, Azzariti A, Fransvea E, Porcelli L, Antonaci S and Paradiso A: Laminin-5 offsets the efficacy of gefitinib ('Iressa') in hepatocellular carcinoma cells. Br J Cancer 91: 1964-1969, 2004.

41. Henderson YC, Wang E and Clayman GL: Genotypic analysis of tumor suppressor genes PTEN/MMAC1 and p53 in head and neck squamous cell carcinomas. Laryngoscope 108: 1553-1556, 1998.

42. Puhringer-Oppermann FA, Stein HJ and Sarbia M: Lack of EGFR gene mutations in exons 19 and 21 in esophageal (Barrett's) adenocarcinomas. Dis Esophagus 20: 9-11, 2007. 